\title{
Going Beyond Customers - A Business Segmentation Approach Using Network Pictures to Identify Network Segments
}

\author{
Stephan C. Henneberg • Stefanos Mouzas • Peter Naudé
}

\begin{abstract}
Existing approaches to segmentation, in particular business segmentation, are often conceptualized and applied in a limiting way, providing a narrow interpretation of the surrounding business network. This could be attributed to a rather myopic view of the multiple complexities and indirect links inherent in networks of business exchange relationships. The task for companies developing innovative segmentation approaches is to simultaneously enhance the company's understanding of downstream as well as upstream preferences and resources, while going beyond immediate interaction partners to include relevant indirect business partners. The challenge is therefore not to identify attractive customer segments, but attractive network segments. As such, the managerial challenge becomes one of creating a business network segmentation from the perspective of a focal company within this network, taking a far wider interpretation of the concept of segmentation. Using the concept of network pictures, we outline the different dimensions that are important within a business network segmentation, and exemplify their use through a case study of an entrepreneurial company. Our study contributes to the literature by providing a detailed example of a practical application of abstract concepts, in this case the translation of the network picture concept into a way to apply a business network segmentation to an entrepreneurial context.
\end{abstract}

Keywords: Business segmentation $\cdot$ Network pictures $\cdot$ Business networks $\cdot$ Concept application

(C) Gabler-Verlag 2009

S. C. Henneberg $(\varangle) \cdot$ P. Naudé

Manchester Business School, Manchester University, Manchester, UK

e-mail: Stephan.Henneberg@mbs.ac.uk

S. Mouzas

Lancaster University Management School, Lancaster, UK 


\section{Introduction}

Segmentation approaches are a very important aspect of the toolkit of both marketing managers as well as business and account managers. The different approaches provide a way to better understand the complexities of diverse customer preferences which exist within a market, and allow for a more focused resource allocation decision by selecting attractive customer groups which fit against a company's capability set. As such, segmentation is crucial in developing offerings that fit the specific needs and wants of a clearlydefined customer target. Existing approaches to segmentation, in particular business segmentation, however, are often conceptualized in a limiting way, i.e. provide a narrow interpretation of the surrounding business network in which a company is embedded. As such, they are primarily focused at identifying attractive customer segments in a market. This might be attributed to a rather myopic view of the multiple complexities, and indirect links inherent in business networks. Consequently, existing approaches to business segmentation are rather static (Dyer, Dong, and Chu 1998, Millier 2000) as they do not take into account the intrinsic dynamism and volatility of existing and emerging preferences in business networks (Blocker and Flint 2007).

In this study, we posit that the challenge for companies developing innovative segmentation approaches in a business market environment is to simultaneously enhance their company's understanding of downstream as well as upstream preferences and resources, while going beyond immediate interaction partners to include relevant indirect business partners (Normann and Ramirez 1993). We therefore posit that business segmentation ought to identify attractive network segments, not just customer segments. Consider, for example, the upstream and downstream preferences and capabilities in the automotive industry. While the immediate customers of a brake lining manufacturer are automotive suppliers which use the break lining in their assembly of a braking system, the complete offering is sold to an automotive manufacturer which uses such braking systems in its offerings to downstream industrial customers and consumers. A car that comprises the component of the brake lining is then sold through intermediary dealers to a final customer. In this business network, the direct customer of the brake lining manufacturer may be identified as the original-equipment manufacturer. Nonetheless, going beyond customers to other downstream customers, may be more important for the demand specification of the break lining. Other downstream customer groups, such as the final customers, may demand certain offering characteristics in line with their expectations for the overall car offering. For example, they may expect specific no-wear ceramic brakes with a premium status sportscar offering. Similarly, going beyond immediate suppliers to other upstream suppliers may be crucial in achieving a certain technological leadership associated with the brakes for a specific car model.

The managerial challenge for companies becomes, therefore, one of creating a business network segmentation from the perspective of a focal company within this network, taking a far wider interpretation of the concept of segmentation. This wider interpretation enriches a mere customer-based view of segmentation in two ways: firstly, by going beyond customers and incorporating considerations of indirect customers, and secondly, by including a supply perspective to the aspect of matching customer demand with company capabilities. Both aspects are incorporated in identifying attractive network segments as 
part of a business network segmentation. In this way, we approach the issue of segmentation in business markets from a 'sense-making' perspective (Johanson and Mattsson 1992). We argue that managers need to think about how to understand the environment in order to make efficient and effective decisions about resource allocation, strategic positioning, and networking activities in general. Making sense of the embedding landscape means, first and foremost, focusing on certain aspects of this landscape and leaving out others. Thus, segmentation in this definition becomes an individual as well as a collective phenomenon of sense-making (Neill, McKee, and Rose 2007, Weick 1995). With this objective in mind, we link segmentation to targeting and positioning aspects of a company within business networks (Ford et al. 2003).

In order to address this challenge, and to address the research question of how manager's subjective understanding of the business network can be used practically in a wide segmentation approach, we will use a case study to exemplify a business network segmentation based on 'network pictures', a cognitive mapping tool encouraging the incorporation of a wider range of actors, where the focal variables are the broader embedded business interactions taking place between companies, i.e. a system not restricted to simply the buying/supplying partners (Ford and Håkansson 2006, Henneberg, Mouzas, and Naudé 2006). Network pictures are based on a manager's subjective understanding of the business relationships deemed to be relevant, i.e. certain actor, activity, and resource ties are selected and prioritized by the relevant managers to provide a base for targeting crucial (direct or indirect) relationships. Using this case study, certain criteria for a wider interpretation of the segmentation approach are discussed, in line with calls for more research on strategic issues of business segmentation (Goller, Hogg, and Kalafatis 2002). Our main contribution lies therefore in the clarification of the practice of an alternative business segmentation approach via a case study. We are applying existing concepts (such as network pictures) and show their relevance as an application for managers. As such, we bridge the gap of mode 1 research on the one hand (consisting of theoretical constructs such as network pictures), and mode 2 knowledge which exemplifies the relevance of these concepts by showing their context of application (Gibbons et al. 1994, Starkey and Madan 2001) and thus 'naturalize' the underlying core concepts (Hatchuel 2001). Arguably, we go beyond a mere discussion of the application of segmentation issues and link the concept to targeting and positioning issues. As such, the application of a business network segmentation approach enriches the literature on business marketing in general, and business segmentation (as well as targeting and positioning) in particular, and provides a possible operationalization and application context of the network view of business markets (Anderson, Håkansson, and Johanson 1994, Ritter 2000). However, it is not meant as another segmentation process model, but rather as mode 2 knowledge which enriches existing segmentation theory by taking a broader network perspective.

Our article will progress as follows: We first discuss the applicability of the concept of network pictures to segmentation approaches. Following on from this, we propose the relevant segmentation logic and variables and exemplify the proposed method by providing a rich description of an entrepreneurial case situation using such a sense-making tool for segmentation purposes. A summary as well as a discussion of the implications for research and practical business marketing applications, as well as a discussion of limitations of the study, conclude the article. 


\section{Network Pictures and Business Markets}

One of the main factors determining success in modern markets is the understanding of complex business environments in order to strategically position a company vis-à-vis competitors and customers, and accordingly to allocate resources optimally (Achrol 1997, Achrol and Kotler 1999, Stabell and Fjeldstad 1998). Value-creating systems of manifold actors and their complex interactions provide challenges as well as options for marketing strategy (Normann and Ramirez 1993, Parolini 1999). Understanding this environment is a crucial aspect of a company's sense-making capabilities, which can be shown to be a precursor to an adaptive strategic marketing response as exemplified in developing appropriate offerings, differentiated from the competition and providing superior levels of value to both relevant downstream organizations (Neill, McKee, and Rose 2007) and final customers (Henneberg and Mouzas 2007).

Business or industrial segmentation is a well researched field and in this article we cannot provide more than a parsimonious discussion of some key sources. Seminal articles such as Wind and Cardozo (1974), Bonoma and Shapiro (1984), and Shapiro and Bonoma (1984) were followed by a continuous stream of publications. Some main segmentation variables used in these articles are customer characteristics such as size, volume or location, the customer decision-making unit, as well as buying decision process characteristics or the buying situation (Cardozo 1980, Crittenden, Crittenden, Muzyka 2002, Griffith and Pol 1994, Kalafatis and Cheston 1997). Needs- or benefit-based models have been widely applied, also in the supply chain literature (Albert 2003, Bennion 1987, Brown, Shivashankar, and Brucker 1989, Kluyver and Whitlark 1986, Moriarty and Reibstein 1986). Often nested (multi-step) models for segmentation are proposed (Bonoma and Shapiro 1984, Cheron and Kleinschmidt 1985, Dibb and Simkin 1997, Plank 1985), and segmentation models have been related to the complexity of business market situations (Freytag and Clarke 2001). Furthermore, issues surrounding the implementation of business segmentations are still debated (Dibb and Simkin 2001, Palmer and Millier 2004), as are practical problems (Abratt 1993, Kalafatis and Cheston 1997).

While many different business segmentation concepts are proposed, these are often criticised for manifold reasons (Plank 1985). For example, it is argued that they are not dynamic, i.e. do not take account of instabilities in the customer market (Blocker and Flint 2007), that they are mechanistic (Millier 2000), or that they do not take into account contextual or strategic variables (such as the wider business network) (Goller, Hogg, and Kalafatis 2002, Palmer and Millier 2004, Piercy and Morgan 1993, Verhallen, Frambach, and Prabhu 1998).

Our starting point is that a business segmentation in its widest interpretation needs to provide an integrated understanding of the complex business network in which companies are embedded (Ford et al., 2003). This means going beyond customer segments. We therefore arguably change the domain for our definition of segmentation approaches using a network perspective (Ford and Håkansson 2006). However, such a segmentation approach also needs to focus on relevant and actionable aspects of this environment. This is due to the fact that the embedding network is objectively borderless and, therefore, super-complex (Holmen and Pedersen 2003). Using the subjective understanding of managers relating to their perceived business network, the concept of network pictures 
provides such an actionable frame. We, therefore, propose that using network pictures provides a sense-making lens which fulfils the demands of such a business network segmentation. These demands include specifically the incorporation of relevant downstream customer preferences on the one hand, and upstream supplier capabilities on the other (Henneberg and Mouzas 2007). Used in this way, network pictures address the main shortcomings of a narrow conceptualisation of business segmentation.

The concept of network pictures is based on Asch's (1952) notion of 'activity systems' and refers to the different understanding that players have of the business network in which their focal company is operating. They are, therefore, based on managers' subjective, idiosyncratic sense-making with regard to the main constituting characteristics of the network within which their company is embedded (Borders, Johnston, and Rigdon 2001, Ford and Håkansson 2006, Ford et al. 2003, Henneberg, Mouzas, and Naudé 2006). As such, network pictures constitute a business market-specific cognitive map in the tradition of Tolman (1948) and Huff (1990), analogous to the intra-organizational sense-making literature (Daft and Weick 1984, Gioia and Chittipeddi 1991). Network pictures provide the manager with a 'narrative' indicating how their business environment 'works'. This is necessary as managers usually have limited direct experience with only a subset of the business relationships and interdependencies which characterize the value-creating business system in which they operate. This is related to the fact that "observers seem[.] to have acquired knowledge of many of the spatial relations in a complex spatial layout from direct experience with only a small subset of those relations" (Pick 1999: 135). By providing a consistent framework, network pictures allow managers to build imaginary connections between events, objects and situations in their business environments, so that these become meaningful to them and their organizations (Smircich and Stubbart 1985).

Network pictures leave out aspects of the business network which individual managers do not believe to be important (Henneberg, Mouzas, and Naudé 2006). However, they include not only what managers perceive to be their relevant environment and how it 'works', but also what potential options or opportunities result from these constellations (Möller and Svahn 2003, Spender 1989). A network picture, therefore, covers potentially a wide range of the business network in which a focal company is embedded: direct and indirect customers and suppliers, competitors, influencing forces, but also others actors such as EDI-linked company clusters. Through social interactions within the company, individual network pictures are implicitly exchanged, i.e. different 'network theories' are tested against each other and consequently adapted. In what has been described as the formation of network insight (Mouzas, Henneberg, and Naudé 2008), such organizational network pictures provide the (often implicit) foundation for strategic decision-making and option analysis and selection. Seen in this wider context, business segmentation is a necessary subset of this network insight, and part of a collective sense-making activity of any company's management (Henneberg, Mouzas, and Naudé 2007).

To date, not many studies have operationalized the concept of network pictures or linked the concept to managerial practice. Thus the translation of mode 1 knowledge (the concept of network pictures) into mode 2 (for example the application context for the use of network pictures in a business segmentation setting) has not been achieved (Gibbons et al. 1994). This is astonishing as the concept is implicated in a wider 'network model' developed by Ford et al. (2003) which, together with the constructs of 'networking' and 'network out- 
comes' provides an underlying framework to understand and guide business interactions within the Industrial Marketing \& Purchasing (IMP) group (Ford and Håkansson 2006). Ford and Redwood (2005) have used aggregated network pictures in a longitudinal study to depict the developments of a whole industry, based on a focal company perspective. On the level of individual manager's network pictures, Ford and Ramos $(2006 ; 2007)$ have developed a model which uses several dimensions to analyse the cognitive models employed by different individuals in different companies and networks. Similarly, Henneberg, Mouzas, and Naudé (2006) have proposed an eight-dimensional 'open' construct of network pictures which they show to be useful in understanding the complexities of individual managers' sense-making of the business environment in relationship to the specific strategic or operational task these managers fulfil. A similar concept has been used to understand the changing network pictures where the business environment is dramatically altered during merger and acquisition activity (Öberg, Henneberg, and Mouzas 2007).

Due to the flexibility of the model, and the fact that it provides a tested 'dimension pool' resulting from nomothetic research (Daniels, Johnson, and Chernatony 1994, Eden and Ackermann 1998), we use the operationalisation proposed by Henneberg, Mouzas, and Naudé (2006) to develop a business network segmentation approach. However, this does not preclude adding or substituting further dimensions to the segmentation approach, as our argument is aimed mainly at showing the relevance and conceptual integrity of a wider perspective of business segmentation aimed at identifying network segments.

\section{A Business Network Segmentation Approach}

The proposed business network segmentation approach uses the concept of network pictures as "a pattern of action as well as a pattern for action" (Neisser 1967: 56, emphasis in original). The perspective of a focal company is employed, which uses business segmentation as a strategic marketing device to connect the company to its business environment.

\section{Business Network Segmentation Structure}

Such a business network segmentation based on network pictures, therefore, provides an understanding of several different aspects important for a wider perspective of business segmentation, namely:

- The relevant preference structures of direct customers, as well as the dependencies of these preference constellations on indirect customers further downstream

- The relevant resource and capability distribution in the supply network necessary to provide offerings which satisfy different customer preferences (again, this can include both direct and secondary suppliers which can be mobilized, either directly or indirectly, via other companies within the network)

- The linkages between downstream customer preference structures and upstream supply capabilities.

These three aspects define the outcome of a business network segmentation as the identification of network segments, contrasting this with the outcome of a normal segmentation 
as customer segments. A network view enables a segmentation process to directly relate to strategic contingency approaches which posit that successful performance results from aligning design variables on the one hand (i.e. endogenous variables such as the organizational structure of a firm, or the offering and the capabilities necessary to provide it) and context variables on the other (i.e. exogenous variables such as environmental or market characteristics such as customer preferences) (Powell 1992).

Figure 1 provides a schematic presentation of a hypothesized business network segmentation. The network picture associated with the focal company (FC) incorporates a limited number of customer preference segments as well as supplier capability segments. Each of these segments is homogenous according to either preference characteristics or supply capabilities and can consist of one or many organizations. Although FC perceives that there exist four distinct customer preference segments, only two are assessed as viable exchange partners (i.e. interactions are possible). However, the other segments are also included in the overall business network segmentation logic, as they indirectly influence the options available to FC and its customers. Focusing on customer preference segment $\mathrm{C} 1$, the network perspective clarifies that the relevant preferences are not immanent to this segment, but determined by understanding the business needs of another downstream segment $\mathrm{C} 2$ with which FC has no immediate interaction. Therefore, the preferences of $\mathrm{C} 1$ are derived from $\mathrm{C} 2$. Consider, for example, a packaging supplier for cereals which may need to understand the shelving requirements of major food retailers

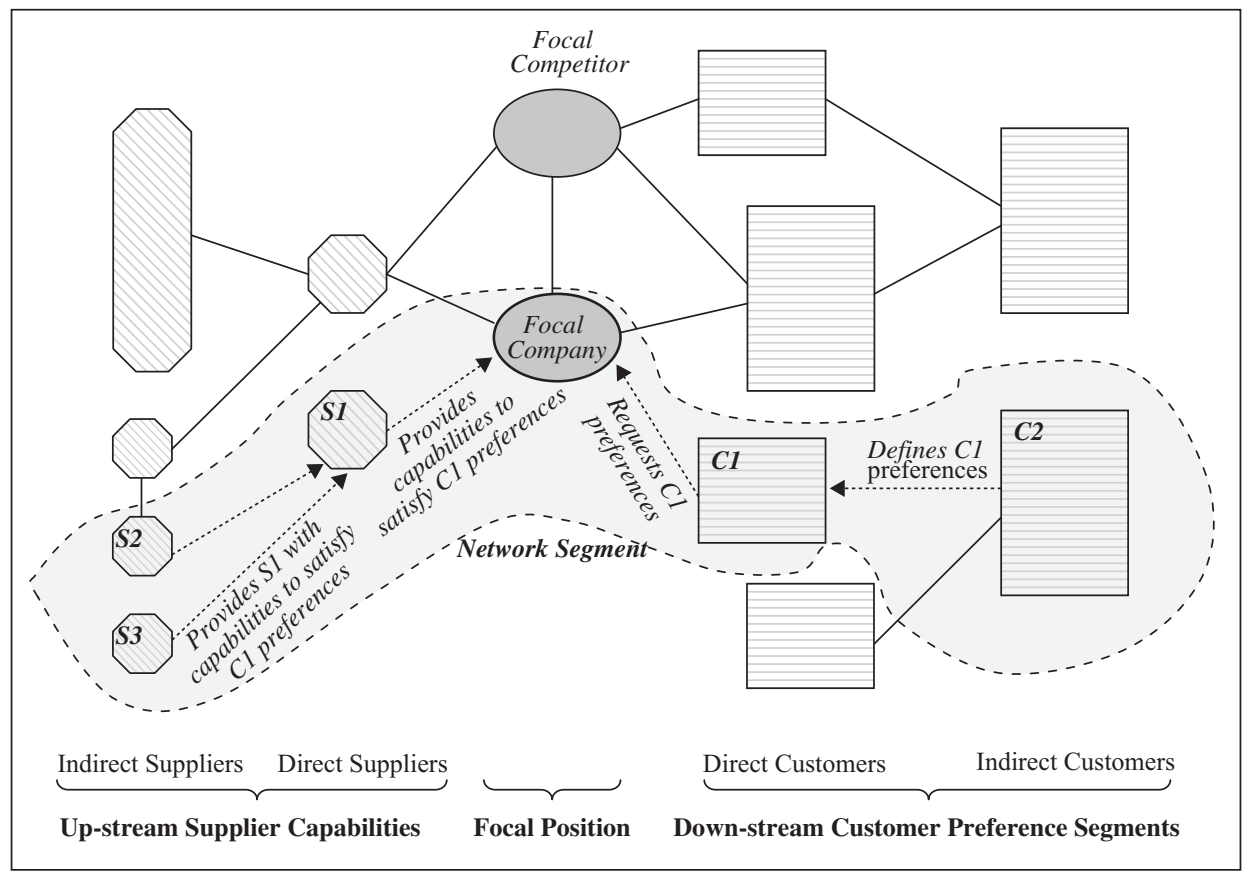

Figure 1: Schematic Representation of a Business Network Segmentation; dotted line delineates one possible network segment 
(in terms of sizing, transport logistics system, point-of-sales visibility requirements) in order to develop an offering which can be sold to the packaging supplier's immediate customer, the cereal manufacturer. For the purpose of an optimal offering development, such a packaging supplier needs to take into account the needs and wants of immediate customers plus those of other relevant (indirect) down-stream customers.

In potentially addressing the preferences by offering a specific product or service, certain capabilities are necessary to create this offering. These will not normally all be owned by FC but are related to the resources supplied by upstream exchange partners. As the schematic business network segmentation shows, FC identifies two clusters of companies with distinct resource provisions as relevant for its offerings. However, with regard to fulfilling the preferences of $\mathrm{C} 1$, only the supplying companies of S1 are perceived as relevant, i.e. only $\mathrm{S} 1$ has the relevant resources and capabilities that, together with the transformation activities of FC, will address the needs of $\mathrm{C} 1$ (and C2). While S1, therefore, is identified as a crucial resource bottle-neck, its capabilities are sourced from at least two different supply clusters (S2 and S3), i.e. FC would not be dependent on one specific technology, process, or knowledge capability but could mobilize the necessary resources in two different ways. However, in its current network constellation, FC always needs the relationship via S1 to access these crucial capabilities for satisfying $\mathrm{C} 1$ and C2.

FC has therefore identified one possible network segment which relates the capabilities of S1-3 via its own transformation process to the needs of C1-2. The schematic example therefore illustrates that network pictures provide a possible structural foundation for a wider interpretation of a business segmentation approach. In order to operationalize and exemplify this approach, the segmentation-relevant variables used for generating network pictures as part of a business network segmentation approach need clarification. Otherwise it remains unclear how the network segments within an overall network picture are 'created'.

\section{Business Network Segmentation Variables}

As outlined above, we loosely use the eight dimensions identified in Henneberg, Mouzas and Naudé (2006) and adapt them to the suggested construct model by Ford and Ramos (2007). These dimensions (in their entirety, or based on a selection of some of them) provide the segmentation variables to identify relevant actors (up-stream and down-stream businesses), their network position, and their capability and preference similarities based on resource and activity ties. A network picture as foundation for a business network segmentation is characterized by:

- Boundaries: This includes both 'depth' and 'width,' of up-stream and down-stream business which are deemed important, either because they provide directly or indirectly important capabilities, or because they represent directly or indirectly certain preferences clusters. Similar to the notion of network horizon (Holmen and Pedersen 2003), boundary decisions within network pictures determine to some extent the complexity of the segmentation. Note that the inclusion of more down-stream preference clusters will normally mean an increase in the number of up-stream supply networks 
with different capabilities which are corresponding to the preference structures. We recognize that the boundaries are essentially artificial (Ford et al., 2002), since 'networks are in principle borderless' (Holmen and Pedersen 2003: 410) and are, therefore, part of the subjective decision by managers regarding the best 'cut-off' for the network picture.

- Centre/Periphery: Network pictures may have a clear centre, a focal company or perhaps a focal relationship (Ford et al., 2002). However, for the purpose of a business network segmentation, the company doing the segmentation will appear centrally. Thus, a periphery is also required, although it can be argued that for general network pictures (i.e. not used for segmentation purposes) this is not a necessary requirement (Henneberg, Mouzas, and Naudé 2006). Periphery decisions as part of network picture configurations are closely linked to boundary decisions.

- Actors/Activities/Resources: This constitutes arguably the pivotal variable group of a business network segmentation. A network picture will implicitly incorporate different types of actors, activities or resources (Håkansson and Johanson 1992, Håkansson and Snehota 1995). The actors are depicted as homogenous groups of individuals or companies with regard to the activity and exchange patterns that characterize their direct or indirect interactions with the focal company, and with regard to their resource ties and capability dependencies.

- Focus: Focus in network pictures refers to whether they are using an entity-related perspective versus a connectivity-related perspective. In other words, are networks constituted as 'sets of connected firms [actors]' or as 'sets of connected relationships between firms?' (Anderson, Håkansson, and Johanson 1994: 1). The schematic representation in Fig. 1 is based on entities. However, business network segmentation may also be constructed around relationships, e.g. those embedded in integrative technologies like JIT or EDI systems, and ERP or ECR applications.

- Directionality of Interactions: Interaction patterns lie at the heart of networks and of network pictures. The dimension of directionality refers to the two different aspects of the flow and reciprocation of goods, knowledge or other entities, and of the interdependence of the business relationships, examining whether or not a primary relationship has an impact on a secondary one (relationship A is constituent on relationship B) and what quality this interdependence has ('positive' or 'negative') (Ritter 2000).

- Time/Task: A network picture also provides information regarding the time horizon involved (Ganesan 1994). Network pictures may represent singular relationships, where a network is designed to exploit a short-term one-off commercial task or opportunity such as a campaign or a project or, at the other extreme, may represent an on-going longer term relationship that is spread over a longer time-frame and which consists of many more, on-going adaptive offerings (Weick 1995). In case of network pictures underpinning a business network segmentation, the task is clearly skewed toward longer-term and strategic considerations.

- Power: Network theory describes the boundaries between entities as conceptually blurred by the existence of relationships (Anderson, Håkansson, and Johanson 1994, Holmen and Pedersen 2003), and tempered by the relative power of the parties involved (Håkansson and Gadde 1992). This segmentation aspect can be represented as part of network pictures by indicating the extent to which the actors, resources or 
capabilities are perceived as being independent or dependent upon each other within their network of relationships, specifically in the matching of supply-chain capabilities and customer opportunities. This segmentation variable also covers the strength of the relationship: there are both strong and weak ties (Granovetter 1973), and there is strong or weak commitment (Ganesan 1994), which may or may not correlate with the extent to which the different parties are dependent upon each other.

- Environment: The final segmentation variable that may form part of the network picture-based business network segmentation is the external environment: aspects that are outside the immediate 'visibility' of the network picture, i.e. whose position lies outside the boundary, but whose interdependency with network picture characteristics may be of importance in the future and could, therefore, possibly influence the outcome of how the network picture evolves. It comprises those forces that the managers involved cannot clearly describe as being integral, and yet whose characteristics they are aware of, and whose potential influence can alter the network (Anderson, Håkansson, and Johanson 1994, Holmen and Pedersen 2003). Inclusion of environmental network pictures ensures that the business network segmentation remains adaptable to future developments.

As Henneberg, Mouzas, and Naudé (2006) have shown, the use of many of these segmentation variables as part of network pictures are task-specific, in that certain network picture constellations which use different variable combinations from each other are perceived by managers to be better aligned with the demands of certain tasks. For a business network segmentation, the 'world-model' as well as the 'politics-model' (Henneberg, Mouzas, and Naudé 2006) conceptually provide the most likely candidates for a strategically-oriented, power and independence-centred sense-making perspective. To exemplify the application of the concept of network pictures for a business network segmentation a specific case example is now described. This case study provides an understanding of network pictures in a mode 2 knowledge situation, i.e. as a tool used in addressing a business network segmentation issue.

\section{Case Example: GymTron Business Network Segmentation}

\section{Case Setting and Research Design}

GymTron $^{1}$ is a start-up company in the sports and fitness market in the South-West of the United Kingdom. It developed out of a research project at the engineering and sports science departments of a leading UK university and was subsequently founded in 2004 as a commercial company residing within the university's incubator facility. It is currently (2008) a well established niche player in the European fitness market. The offering which finally resulted from the strategic considerations based on the business network segmentation logic was a combined hardware/software solution for the customer loyalty management of individual fitness clubs. This solution was based on providing commonly 
used fitness machines (cardio-vascular as well as performance machines) which are linked to each other via EDI. Therefore, for each person a 'training performance monitor' can be calculated which can be used for several purposes: medical monitoring, session training advice, customer loyalty management, etc. The overarching focus is on customer management, by providing them with suggestions for training schedules, by offering promotional activities ('your performance schedule shows that you would benefit from spinning activities, please check out our spinning classes to which your friends Sonja and Tony have subscribed as well'), or by linking individual customer activities with the training activities of their friends. This provides a sophisticated offering for fitness clubs to understand their customers by integrating behavioural and social data with training and medical information which are linked to monitoring individual sport equipment. Although this is intended to work within the realm of individual fitness clubs, networking between clubs, e.g. for smaller fitness chains, is also possible.

The case study was part of a multi-company qualitative analysis of the business relationships and nets which start-up companies use to mobilize the necessary resources and capabilities. All companies, including GymTron, identified 'knowledge' as the most important asset which they needed to secure via manifold business relationships with customers, suppliers, and other indirect exchange partners. The empirical plane of the case study results from an analysis of the knowledge net relationship which GymTron built, maintained, and dissolved during a 10 month period in 2004/5. This period characterizes what Swart and Henneberg (2007) have called the commercialisation phase of networking, i.e. in this phase the emphasis is on addressing crucial 'knowledge holes' based on initial business model conceptualisations to formally establish the viability of the business venture and to clearly define target markets and the corresponding resource suppliers. As such, the commercialisation phase is the first phase in the life of the entrepreneurial company in which strategic marketing options, including segmentation/targeting/positioning are defined and traded-off against each other.

The research design was based on multiple interactions with the four key employees (founders) of GymTron. These interactions, within the time period of 10 months, consisted of multiple in-depth interviews with each employee (at least once every two months), network picture eliciting sessions (at least three sessions within the research period), as well as observations of key decision-making meetings and an analysis of key strategic and marketing documents. For example, the researchers were present as observers at a dozen board level meetings and received the minutes of all other board meetings. Additionally, several university incubator employees plus selected customers and suppliers (altogether eight respondents) were also interviewed and network picture eliciting sessions were employed. These multiple and longitudinal data points allowed for a triangulation of the findings as well as for a tentative understanding of the dynamics regarding the strategic orientation of GymTron as an embryonic venture (Dubois and Gadde 2002). We used established content analyses procedures to aggregate the data (Krippendorff 2004). Data analysis involved critical examination, evaluation, categorization, and recombination of the empirical evidence collected (Glaser and Strauss 1967, Strauss and Corbin 1998). Casing was used to integrate the findings into a narrative, in line with Ragin's (1992) suggestions: "...casing is an essential part of the process of producing theoretically structured descriptions of social life and of using empirical evidence to articulate theories... 
By limiting the empirical world in different ways, it is possible to connect it to theoretical ideas that are general, imprecise, but dynamic verbal statements" (225). The following observations are a summary of the findings which were also discussed with GymTron employees. Based on this raw data, the following narrative about the development of a segmentation based on a network picture concept was derived.

\section{GymTron Business Network Segmentation}

The founders of GymTron realized early on while managing their start-up that after the initial conceptualisation stage which provided them with what they called an idea for a 'sunrise offering', they needed to focus on the overall business network constellation which would enable the commercialisation of this idea (Swart and Henneberg 2007). This included a segmentation strategy incorporating supply chains as well as customer networks in order to focus their efforts on one targeting option which allowed them to position themselves in the overall network. To do this, they developed over the 10 month period ever more complex and detailed network pictures which collectively allowed them finally to assess the available options and choose one dominant interaction network (the target network segment) which they needed to mobilize to cultivate and grow their business in the next stage.

The process for collecting theses network pictures was based on bi-weekly meetings of the board (sometimes including key supplier or customer representatives) which started by updating a so-called 'Fitness World Map'. This consisted of a depiction of what the current view of GymTron's founders was of the fitness market, and how they and their business idea fitted into the existing networks: a huge magnetic white-board represented the actors and interactions, the key knowledge and resource holders, the business relationships and their contingencies, etc., with GymTron representing the focal perspective. This network picture was constantly adapted as new insight was gained in between the regular meetings. It was radically re-drawn three times in the 10 month observation period (e.g. the underlying network logic changed from being about fitness machines to fitness club loyalty management after about seven months).

The final network picture which was used to determine the preferred customer and network segment and the necessary resources and capabilities to satisfy the preferences of this segment is depicted in a simplified way in Fig. 2. Only the main actor segments and primary/ secondary business relationships for the selected target network segment are shown. GymTron decided to focus on the customer preferences of 'Social Fitness Enthusiasts', i.e. end consumers who use the gym for fitness and social reasons. This is done mainly in 'Fitness Clubs', mostly chains which are independent of other entertainment offerings (such as fitness clubs integrated in hotel chains). These are identified by GymTron as their direct customer target segment. GymTron's offering is targeted at enabling fitness monitoring as well as an integrated customer loyalty management of the final customers. Therefore, the relevant preference structures which define the network picture's logic of the business network segmentation are based on an amalgamation of the fitness and social needs of the final customer target segment as well as the customer and loyalty management requirements of the fitness clubs. The network picture also shows that these preferences are mediated primarily through the preferred channel for the acquisition of 


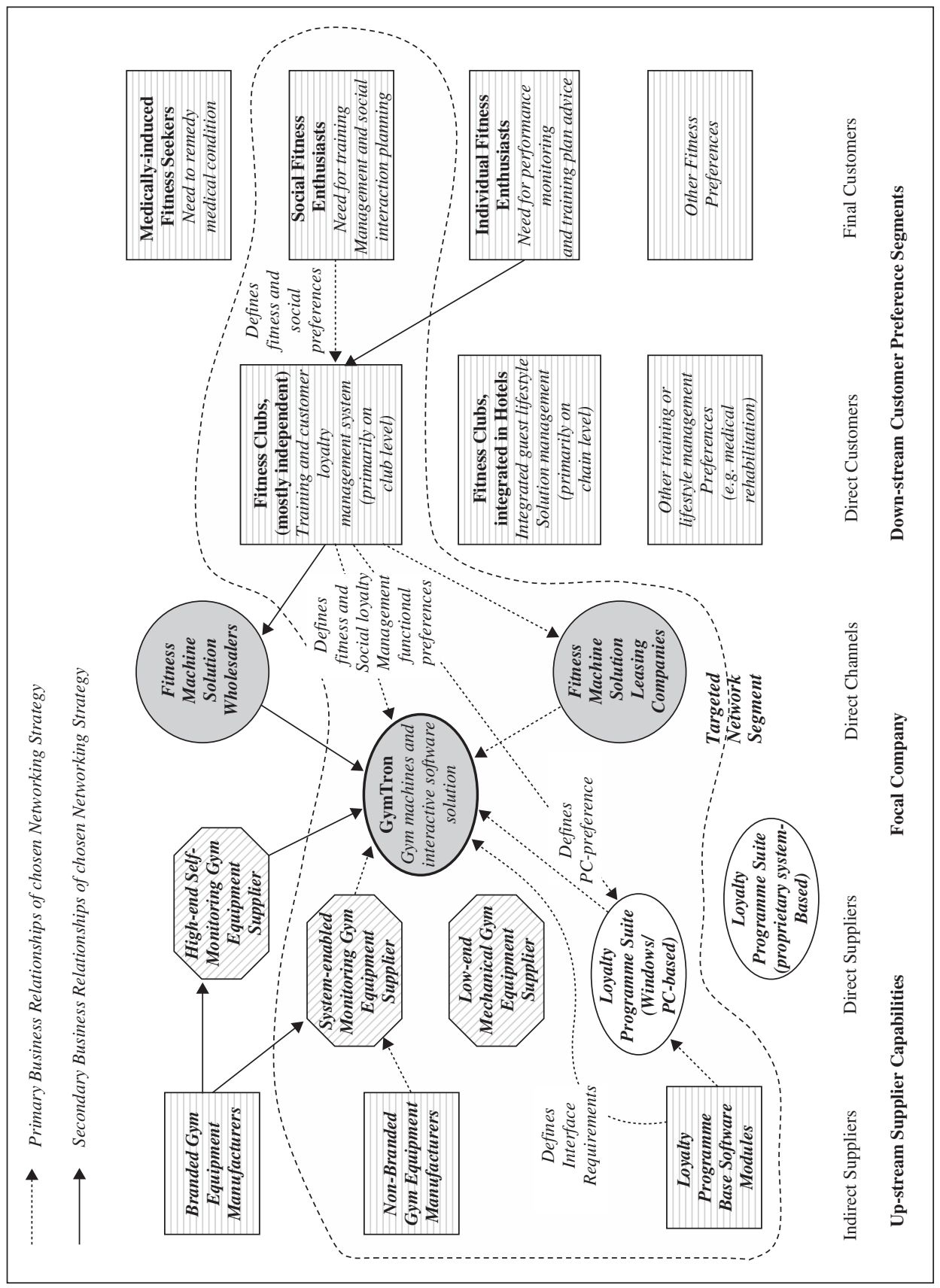

Figure 2: GymTron Network Picture and Dominant Strategic Business Network; dotted line delineates the targeted network segment 
fitness systems, i.e. 'Fitness Machine Solution Leasing Companies' which need to be mobilized as the most important distribution channel for GymTron.

The only capability GymTron provides for satisfying the needs of its direct and final customers is a proprietary software system which is compatible with industry-standard person-recognition systems (e.g. swipe card or fingerprint recognition of individual customer usage of fitness machines). As such, it enables the integration of software and hardware products and services, coming from two different supply networks, into a training and customer loyalty management system. However, at this level the interdependences between customer preference targets and supply network capabilities become important. The loyalty software solution preferred by the direct customers needed to be a Windows version for industry-norm specific PCs as most of the companies representing the Fitness Club segment had already existing legacy systems (e.g. billing systems, customer databases) with which the new offerings needed to be integrated. This also meant that GymTron had to mobilize the base module providers of the loyalty programme software, to make sure that certain interfaces were pre-programmed into the modules to allow for interaction with the hardware (i.e. the gym equipment). As part of the business network segmentation GymTron's ability to influence and work together with the 'Loyalty Programme Base Software Suppliers' was identified to be central to the functioning of this business network.

On the hardware side, a 'System-enabled Monitoring Gym Equipment Supplier' was needed to deliver a platform which the GymTron software system could link into (therefore, 'low-end gym technology solutions' were not applicable). However, as this increased the solution price, GymTron decided that a viable offering for the Fitness Clubs could only be achieved via the use of non-branded gym equipment hardware. Thus, they negotiated a long-term but flexible agreement with two Taiwanese and Chinese manufacturers with experience in serving the European market.

It is noteworthy that in GymTron's network picture uni-directional interactions (oneway arrows) are used. These centre on GymTron as the focal company. Thus, the perception of GymTron's network is based on two 'flows' (one supply flow, and one demand flow) culminating in their company. While this is contrary to the network concept and the underlying interaction model used within research of the IMP Group (Ford and Håkansson 2006), it is in line with the task-focus of a business network segmentation as being related to one actor (i.e. the company using this segmentation to drive its networking activities). Other research on capturing network pictures found that for different tasks, the subjective network pictures can indeed show a two-way logic. As such, uni-directionality in Fig. 2 represents the 'subjective' way of interpreting the logic of the network as seen by the GymTron managers for a segmentation application. The representation of this logic via one-way arrows is therefore retained as it represents the case study managers' way of thinking.

In retrospect, such a network picture and the resulting targeted network segment seems consistent (and the resulting success of GymTron to some extend corroborates their business network segmentation choices), it represents only one of several possible options which GymTron could have chosen. For example, a focus on 'Medically-Induced Fitness Seekers' as final customers would have meant totally different preferences, offering characteristics, and distribution network, resulting in different choices of supply partners. 
Thus GymTron had to identify and then choose complex network segments to target one of them.

\section{GymTron Network Picture Analysis of Segmentation Variables}

Table 1 summarises the network picture and highlights the network segment on which GymTron's final business network segmentation was based. It also outlines the usefulness of the dimensional characteristics for the practical application as part of a strategic segmentation by GymTron. Using the proposed eight dimensions of network pictures to characterize GymTron's business segmentation approach, the selected boundaries are relative complex (three-step downstream, two-step up-stream). However, competition was excluded from the picture and relegated to the general business environment. Interestingly, GymTron insisted on incorporating final customer preferences, i.e. it employed a wide value horizon (Henneberg and Mouzas 2007). The ratio of indirect to direct business relationships is also high (about two-to-one). It is noteworthy that the boundaries firstly increased during the 10 month observation period due to the learning process of the GymTron managers, while the overall network picture contracted in the last two months when strategic decisions were needed.

In line with expectations for a business segmentation, the network picture had a clear centre. However, GymTron included two supply peripheries, one for loyalty programme modules (software) and one for gym equipment (hardware). Actors/activities/resources are used to characterize the preference and resource capability groups. Activity and resource ties are mostly used to show direct and indirect demand preferences, interestingly also between customer and supply players circumventing the focal company. This contingency (between the software system demands of Fitness Clubs on the one hand, and Loyalty Programme Suit providers on the other) depicts a crucial interdependence structure. Without its realisation in GymTron's network picture, inconsistent networking and mobilisation activities could have resulted, and another network segment may have been targeted. The focus of the chosen network picture is entity-based, understood as clusters of preferences or resource provision. Connectivity is not understood to be the defining aspect of the business network but a result of the networking activities of its members. This is in line with the managerial emphasis of business segmentation approaches. GymTron also decided with regard to the directionality of interactions to minimize the depiction of relevant secondary dependencies. In fact, the board voted on which of the manifold secondary influences should direct their strategic segmentation and targeting decision. They decided to include only those related to final customer segment preferences and those with regard to interface requirement for software-hardware interaction as these were deemed to be the be crucial for their network understanding. A long-term horizon regarding the task-orientation was chosen. However, as the business was in its start-up phase and most of the business relationships represented in the network picture were tentative, GymTron tried to incorporate more short-term considerations (mainly by developing an alternative supply and channel network segmentation for another final customer segments, i.e. 'Medically-induced Fitness Seekers'). Interestingly enough, GymTron did not imbue its network picture with a power-related perspective, nor is there a special emphasis on tie strength (except in the resulting networking activities of forging 
Table 1: GymTron's Business Network Segmentation Characteristics

\begin{tabular}{|c|c|c|}
\hline $\begin{array}{l}\text { Network Picture } \\
\text { Dimensions }\end{array}$ & $\begin{array}{l}\text { GymTron Dimensional } \\
\text { Characteristics }\end{array}$ & $\begin{array}{l}\text { Usefulness of Dimensional Cha- } \\
\text { racteristics for Business Network } \\
\text { Segmentation }\end{array}$ \\
\hline Boundaries & $\begin{array}{l}\text { Relatively wide boundaries, espe- } \\
\text { cially downstream; competition } \\
\text { excluded from picture }\end{array}$ & $\begin{array}{l}\text { Important dimensional characteristic } \\
\text { to understand indirect business relati- } \\
\text { onships, e.g. derived demand patterns } \\
\text { as part of a wide value horizon }\end{array}$ \\
\hline Centre/Periphery & $\begin{array}{l}\text { Clear centre identified (GymTron) } \\
\text { as part of proprietary segmentation } \\
\text { exercise; use of two distinct supply } \\
\text { periphery constellations }\end{array}$ & $\begin{array}{l}\text { Less important dimensional cha- } \\
\text { racteristic as segmentation practice } \\
\text { presupposes a focal company as the } \\
\text { centre }\end{array}$ \\
\hline $\begin{array}{l}\text { Actor/Activities/ } \\
\text { Resources }\end{array}$ & $\begin{array}{l}\text { Inclusion of final customers; actors } \\
\text { and activities are perceived as main } \\
\text { preference indicators (downstream), } \\
\text { resources as the main capabili- } \\
\text { ty indicator (upstream); several } \\
\text { indirect activities are included to } \\
\text { exemplify interdependencies in the } \\
\text { constellation }\end{array}$ & $\begin{array}{l}\text { Very important dimensional characte- } \\
\text { ristic as it allows GymTron to deve- } \\
\text { lop an understanding of the 'logic' of } \\
\text { the interactions within the network }\end{array}$ \\
\hline Focus & $\begin{array}{l}\text { Entity-based as clusters (i.e. not in- } \\
\text { dividual organizations); connectivi- } \\
\text { ty-based focus is excluded from the } \\
\text { network picture (as it is understood } \\
\text { by GymTron as an option resulting } \\
\text { from understanding the network } \\
\text { constellation) }\end{array}$ & $\begin{array}{l}\text { Less important dimensional characte- } \\
\text { ristic; GymTron also had alternative } \\
\text { business network segmentations } \\
\text { which operated with an individual } \\
\text { company focus (however, this did not } \\
\text { add to the explanatory power of the } \\
\text { business network segmentation) }\end{array}$ \\
\hline $\begin{array}{l}\text { Directionality of } \\
\text { Interactions }\end{array}$ & $\begin{array}{l}\text { Focus on primary directionalities; } \\
\text { only final customer preference- } \\
\text { related secondary directionalities } \\
\text { included }\end{array}$ & $\begin{array}{l}\text { Less important dimensional cha- } \\
\text { racteristic; GymTron intentionally } \\
\text { simplified their network pictures with } \\
\text { regard to this dimension }\end{array}$ \\
\hline Time/Task & $\begin{array}{l}\text { Long-term horizon; however, use of } \\
\text { contingency network constellation } \\
\text { around medically-induced final } \\
\text { customer preferences }\end{array}$ & $\begin{array}{l}\text { Less important dimensional characte- } \\
\text { ristic; focus on long-term horizon } \\
\text { determined by the strategic nature of } \\
\text { a business network segmentation }\end{array}$ \\
\hline Power & Power relationships not used & Neglected dimensional characteristic \\
\hline Environment & $\begin{array}{l}\text { Diffuse understanding of environ- } \\
\text { ment; inclusion of competitors under } \\
\text { this dimension, i.e. without direct } \\
\text { impact on the network constellation } \\
\text { identified }\end{array}$ & $\begin{array}{l}\text { Less important dimensional } \\
\text { characteristic }\end{array}$ \\
\hline
\end{tabular}

a long-term strong tie with certain non-branded gym equipment manufacturers). Further contingencies were also not included as GymTron wanted to strip its business network segmentation to its lowest possible degree of complexity (otherwise it was feared that the simultaneous focus on supply and demand networks would not allow for a meaningful strategic option analysis). 
While the overall GymTron network picture shows many aspect of a world-model in the Henneberg, Mouzas, and Naudé (2006) categorisation of network pictures, its lack of use of the dimension of power and its clear actor-entity focus show some characteristics of a sphere-model. However, network pictures of spheres show no clear focus and do not utilize the task dimension, two characteristics which dominate GymTron's network picture. Thus, the case example shows the specificity and idiosyncratic nature of network pictures, even if they are used intentionally as a strategic management and segmentation tool as was the case for GymTron. Overall, the managers involved in the case study found the segmentation dimensions of focus, centre/periphery, activities/resources, and boundaries (i.e. depth and width of particularly indirect actor relationships) to be the most important characteristics in their cognitive representations of the business environment. The crucial ones related to defining the logic of the network (via the dimension of actor/activities/resources) as well as the complexity (via the dimension of boundaries). Activities and resources as segmentation variables became very important in understanding the relative contribution to the transformation processes within the network, in terms of understanding which actor's activities and resources defined the interface requirements. Boundaries impacted on the complexity of the network pictures used as it limits (or extends) the number of indirect relationships. Achieving a wide value horizon, as GymTron decided to do, meant that complexity was added to the network picture. Understanding indirect relationships, e.g. those existing in the customer or supplier network which lay beyond the sphere of direct interactions of GymTron, was singled out as an important insight the managers accumulated in their network pictures. Only this really allowed them to understand the logic behind different network segments, i.e. what potentially could define these segments. Additionally, centre and periphery considerations became important when assessing different possible network segments vis-à-vis each other: one characteristic used was the fact whether or not GymTron was perceived to form the centre of it (this was the case for the chosen network segment and is somewhat linked to segmentation practice which presupposes a focal company). In summary, the GymTron example showed that for the purpose of a business network segmentation two of the dimensional characteristics proved most useful. Other characteristics added certain limited explanatory aspect, while not being sufficient to enable the application of a wide segmentation perspective.

As part of a segmentation approach, the network pictures allowed GymTron to evaluate alternative network constellations in the sense of creating possible demand chains based on alternative final customer preferences (Henneberg and Mouzas, 2007, Jüttner, Christopher, and Baker 2007). Furthermore, GymTron was able to understand the need to mobilize crucial indirect actor groups as part of their segmentation and networking strategy: loyalty programme software suppliers on the supply side (with the crucial resources regarding interface compatibility), and social fitness enthusiasts on the demand side (with the crucial demand for social linkages) (Albert 2003, Erevelles and Stevenson 2006). While GymTron used network pictures as a meta-perspective (and identified the relevant resource and demand clusters via established segmentation processes), such a wide segmentation approach resulting in an understanding of network segments was deemed crucial to finding an appropriate position as an entrepreneurial company within an established business network. 


\section{Conclusion and Limitations}

The present study exemplifies how specific characteristics of network pictures can be used as part of a business segmentation approach, which goes beyond the traditionally narrow segmentation approaches. The main contribution of such an approach is the practical identification of network segments and the matching of them with internal capabilities of the focal company. As mode 2 knowledge, this practical contextualisation via an application example enriches our understanding of the abstract concept of network pictures. While these have previously been posited as research concepts, their usefulness for managerial application had not been tested. We believe that there are a number of ways in which our practical example compliments existing approaches to business segmentation.

Firstly, numerous segmentation approaches focus solely on the needs of direct buying entities, e.g. other organizations and their buying centres, and do not take into account the fact that such needs may be contingent on the preferences of other indirect actors, e.g. final customers (Ford et al. 2003, Henneberg and Mouzas 2007). This is evident especially in business networks, in which manifold interactions between companies form value-creating systems with significant interdependencies (Parolini 1999). Thus, the fact that different aspects of an offering are based on 'derived demand' in a multi-tiered business network makes a segmentation based on a mere 'direct customer focus' myopic and too restrictive. Secondly, existing segmentation approaches are focussed downstream on the interactions with customers, in line with a classical 'customer orientation' as a key concept of marketing theory. Recent developments, however, stress the importance of taking a wider stakeholder perspective as part of being more market-orientated or a network-oriented (see e.g. Jüttner, Christopher, and Baker 2007). The integration of supply chain considerations, for instance, has been argued to be important (Erevelles and Stevenson 2006). Knowledge of upstream preferences and capabilities, i.e. supplier needs and available resources, can be of crucial importance in business markets. In our case, this is exemplified in GymTron's reliance on certain resources to satisfy distinct customer segment needs. The similarities in the literature between current supply chain management approaches and network approaches in the IMP tradition are a strong indicator of the fact that companies need to have a wider understanding of stakeholder preferences, i.e. going beyond customers and developing a demand chain perspective (Jüttner, Christopher, and Baker 2007). The implication of developing a wider perspective is that segmentation approaches, as well as the resulting targeting and positioning activities, must be linked to an understanding of the resources and capabilities available to satisfy specific preferences. This 'matching' of existing capabilities with market opportunities represents a pivotal strategic concept and is achieved via identifying (and later targeting) network segments. The existing resources and capabilities, however, are not just dependent on the focal company's resource constellation, but include also the capabilities of supplying companies which can be mobilized as part of existing business relationships (Mouzas and Naudé 2007). Pooling or coupling of resources can be described as a dominant logic for business interactions (Stabell and Fjeldstad 1998). Therefore, a linkage of supply-side (upstream) with customer-side (downstream) segmentation via an integrated approach such as network pictures is necessary, and provides an important aspect of the sense- 
making capabilities argued to be of crucial importance for successful adaptive marketing strategies (Neill, McKee, and Rose 2007).

There are certain limitations associated with a business segmentation based on network pictures. While we have shown in a case study how a specific entrepreneurial company has used this approach in its strategic sense-making and ultimately positioning in a business network, no real hard evidence exists about the resulting performance of applying this kind of thinking. Although its usefulness was emphasised by the managers of the case company, and the entrepreneurial venture has subsequently flourished, the success of the chosen network segment vis-à-vis others remains unclear. Thus, further mode 2related research is necessary to understand some of the practical aspects of a business network segmentation based on network pictures. Furthermore, while a business network segmentation may be of use in situations of environmental instability or uncertainty (such as entrepreneurial ventures), no clear prediction can be made about the performance of such an approach for established firms in stable environments. Regarding the usefulness of different dimensions of network pictures for a business network segmentation, further research is needed to understand if the same dimensions of network pictures prove meaningful for the specific task of a business segmentation.

\section{Managerial and Research Implications}

Moving beyond customers and adopting a wider network perspective, companies need to develop new approaches that incorporate the cognitive maps of relevant network characteristics as internalized through the eyes of involved actors. If marketing is essentially about satisfying customer needs, then following a traditional model of segmenting direct customers into groups according to those needs seems to be entirely appropriate. However, we argue that this is hardly ever the case in a business-to-business environment characterised by multiplicity and dynamism. It seems to us that a far more complex reality exists, where the relationship between buyer and seller is often dictated, at least to some degree, by other actors beyond this immediate dyad. It is certainly the case that the roles, technologies, and aspirations of a company's buyers' buyers and customers' customers have a direct effect upon any particular dyadic relationship. But the problem is often far broader than this simple depiction of the relative power of other players within the extended supply chain. As our study shows, it is often the case that not just the needs of buyer's buyers or customers' customers need to be considered, but that there are other companies within the network that have a material impact upon a particular focal relationship. Companies that develop segmentation approaches (as those presented in Fig.1 and 2 and synthesized in Table 1) based on cognitive 'pictures' held by managers as sense-making representations may achieve a better strategic matching between the firm's capabilities and market opportunities, exemplified in network segments. Consider, for example, a firm's capabilities such as those of the furniture retailer IKEA vis-à-vis the 'environment-friendly' market opportunities. Mapping the cognitive maps of relevant network characteristics, as internalized through the eyes of involved actors, allows IKEA to work jointly with pulp and paper suppliers on a new product development project to ensure that all catalogues and printed material are 'green' (Ford et al. 2003). In this way, 
network pictures characteristics, such as a) boundaries, b) centre/periphery, c) actor/activities/resources, d) focus, e) directionality of interactions, f) time/task, g) power, h) environment may become powerful tools for finding and addressing existing and emerging needs in a business network.

If this wider perspective is required to make adequate sense of a particular focal dyad then, we argue, there are vitally important implications for researchers and managers working in the area. The traditional view of segmentation, based upon the needs or other similarities of customers, is in danger of failing. In a corporate world characterized by a multiplicity of interconnections, managers have no alternative but to adopt the methodologically more complex, but more insightful, approach of developing segmentation approaches that examine the wider business network.

The research evidence, hitherto, is that companies face a considerable challenge in integrating disperse network pictures held by various actors (Mouzas, Henneberg, and Naudé 2008, Tsoukas 1996). Researchers need to develop a better understanding of the barriers to developing an amalgamation of dispersed cognitive pictures. This difficulty may be attributed to the fact that actors' network pictures are continually re-configured over time as they might impact on each other at the level of a) individual, b) team, c) company as well as d) inter-company network level (Lyles and Schwenk 1992). One possibility that may help researchers overcome these problems is to develop methods of translating the pluralism of subjective network pictures into an objectified segmentation basis for positioning and targeting. Such an objectified segmentation basis would consist of a set of a) shared data, b) information or c) facts. Business segmentation is, thereby, not simply based on subjective views of actors, but rests on continuous and iterative interplay between the factual physical and social artefacts that surround actors as well as the cognitive schemata shaped from actors' past experience as well as precedents (Mouzas, Henneberg, and Naudé 2008).

\section{Endnote}

1 The case study and company name have been sanitized for confidentiality purposes.

\section{References}

Abratt, R. (1993): Market segmentation practices of industrial marketer, Industrial Marketing Management, 22, pp. 79-84.

Achrol, R. S. (1997): Changes in the theory of interorganizational relations in marketing: Toward a network paradigm, Journal of the Academy of Marketing Science, 25 (1), pp. 56-71.

Achrol, R. S. and Kotler, P. (1999): Marketing in the network economy, Journal of Marketing, 63 (Special Issue), pp. 146-163.

Albert, T. C. (2003): Need-based segmentation and customized communication strategies in a complex-commodity industry: A supply chain study, Industrial Marketing Management, 32, pp. 281-290.

Anderson, J.C., Håkansson, H., and Johanson, J. (1994): Dyadic business relationships within a business network context, Journal of Marketing, 58, pp. 1-15. 
Asch, S. E. (1952): Social Psychology, Prentice Hall, Inglewood Cliffs.

Bennion, M. L. (1987): Segmentation and positioning in a basic industry, Industrial Marketing Management, 16, pp. 9-18.

Blocker, C. P and Flint, D. J. (2007): Customer segments as moving targets: Integrating customer value dynamism into segment instability logic, Industrial Marketing Management, 36, pp. 810-822.

Bonoma, T. V. and Shapiro, B.P. (1984): Evaluating market segmentation approaches, Industrial Marketing Management, 13, pp. 257-268.

Borders, A. L.: Johnston, W. J, and Rigdon, E. E. (2001): Beyond the dyad: Electronic commerce and network perspectives in industrial marketing management, Industrial Marketing Management, 30, pp. 199-205.

Brown, H. E., Shivashankar, R., and Brucker, R. W. (1989): Requirements driven market segmentation, Industrial Marketing Management, 18, pp. 105-112.

Cardozo, R. N. (1980): Situational segmentation of industrial markets, European Journal of Marketing, $14(5 / 6)$, pp. 264-276.

Cheron, E. J. and Kleinschmidt, E. J. (1985): A review of industrial market segmentation research and a proposal for an integrated segmentation framework, International Journal of Research in Marketing, 2, pp. 101-115.

Crittenden, V. L., Crittenden, W., and Muzyka, D. (2002): Segmenting the business-to-business marketplace by product attributes and the decision process, Journal of Strategic Marketing, 10 , pp. 3-20.

Daft, R.L. and Weick, K.E. (1984): Toward a model of organisations as interpretation systems, Academy of Management Review, 9 (2), pp. 284-295.

Daniels, K., Johnson, G., and Chernatony, L. de (1994): Differences in managerial cognitions of competition, British Journal of Management, 5 (Special Issue), pp. 21-29.

Dyer, J.C, Dong, S., and Chu, W. (1998): Strategic supplier segmentation: The next "best practice" in supply chain management, California Management Review, 40 (2), pp. 57-77.

Dibb, S. and Simkin, L. (1997): A program for implementing market segmentation, Journal of Business \& Industrial Marketing, 12 (1), pp. 51-65.

Dibb, S. and Simkin, L. (2001): Market segmentation, Industrial Marketing Management, 39, pp. 609-625.

Dubois, A. and Gadde, L.-E. (2002): Systematic combining: An abductive approach to case research, Journal of Business Research, 55, pp. 553-560.

Eden, C. and Ackermann, F. (1998): Making Strategy, Sage Publications, Thousand Oaks, California.

Erevelles, S. and Stevenson, T. H. (2006): Enhancing the business-to-business supply chain: Insights from partitioning the supply side”, Industrial Marketing Management, 35, pp. 481-492.

Ford, D., Berthon, P., Brown, S., Gadde, L-E., Håkansson, H., Naudé, P., Ritter, T., and Snehota, I. (2002): The Business Marketing Course: Managing in Complex Networks, John Wiley, Chichester.

Ford, D., Gadde, L.-E., Håkansson, H., and Snehota, I. (2003): Managing Business Relationships, Chichester, Wiley.

Ford, D. and Håkansson, H. (2006): The idea of interaction, The IMP Journal, 1 (1), pp. 4-27.

Ford, D. and Ramos, C. (2006): Network pictures: Conceptual development and preliminary findings, in: Proceedings of the 22nd IMP Conference, Milan, Italy, 5-6 September.

Ford, D. and Ramos, C. (2007): Situational factors and network pictures, in Proceedings of the $3^{\text {rd }}$ IMP Asia Conference, Phuket, Thailand, December.

Ford, D. and Redwood, M. (2005): Making sense of network dynamics through network pictures: A longitudinal case study, Industrial Marketing Management, 34 (7), pp. 648-657.

Freytag, P. V. and Clarke, A. H. (2001): Business to business market segmentation, Industrial Marketing Management, 30, pp. 473-486. 
Ganesan, S. (1994): Determinants of long-term orientation in buyer-seller relationships, Journal of Marketing, 58, pp. 1-19.

Gibbons, M., Limoges, L, Nowotny, H., Schwartman, S., Scott, P., and.Trow, M. (1994): The New Production of Knowledge: The Dynamics of Science and Research in Contemporary Societies, Sage, London.

Gioia, D. and Chittipeddi, K. (1991): Sensemaking and sensegiving in strategic change initiation, Strategic Management Journal, 12 (6), pp. 433-448.

Glaser, B. G. and Strauss, A. L. (1967): The Discovery of Grounded Theory - Strategies for Qualitative Research, Weidenfeld \& Nicolson, London.

Goller, S., Hogg, A., and Kalafatis, S. P. (2002): A new research agenda for business segmentation, European Journal of Marketing, 36 (1/2), pp. 252-271.

Granovetter, M. (1973): The strength of weak ties, American Journal of Sociology, 78 (6), pp. $1360-1380$.

Griffith, R.L. and Pol, L.G. (1994): Segmenting industrial markets, Industrial Marketing Management, 23, pp. 39-46.

Håkansson, H., and Gadde, L-E. (1992): Professional Purchasing, Routledge, London.

Håkansson, H. and Johanson, J. (1992): A model of industrial networks, in: Axelsson, B. and Easton G. (eds.): Industrial Networks: A New View of Reality, Routledge, London, pp. 28-34.

Håkansson, H. and Snehota, I. (1995): Analysing business relationships, in: Hakansson, H. and Snehota, I. (eds.): Developing Relationships in Business Networks, Routledge, London, pp. 24-49.

Hatchuel, A. (2001): The two pillars of new management research, British Journal of Management, 12 (Special Issue), pp. S33-S39.

Henneberg, S. C. and Mouzas, S. (2007): Managing the customer horizon, Thexis, 3, pp. 7-10.

Henneberg, S. C., Mouzas, S., and Naudé, P. (2006): Network pictures - Concepts and representations, European Journal of Marketing, 40 (3/4), pp. 408-429.

Holmen, E. and Pedersen, A.-C. (2003): Strategizing through analyzing and influencing the network horizon, Industrial Marketing Management, 32, pp. 409-418.

Huff, A. S. (1990): Mapping strategic thought, in: Huff, A. S. (ed.): Mapping Strategic Thought, Wiley, Chichester, pp. 11-49.

Jüttner, U., Christopher, M., and Baker, S. (2007): Demand chain management integrating marketing and supply chain management, Industrial Marketing Management, 36, pp. 377-392.

Johanson, J. and Mattsson, L.-G. (1992): Network positions and strategic action - An analytical framework, in: Axelsson, B. and Easton, G. (eds.): Industrial Networks: A New View of Reality, Routledge: London, 205-217.

Kalafatis, S. P. and Cheston, V. (1997): Normative models and practical applications of segmentation in business markets, Industrial Marketing Management, 26, pp. 519-530.

Kluyver, C.A. and Whitlark, D.B. (1986): Benefit segmentation for industrial products, Industrial Marketing Management, 15, pp. 273-286.

Krippendorff, K. (2004): Content Analysis, Sage, Thousand Oaks.

Lyles, M. A. and Schwenk, C. R. (1992): Top management, strategy and organizational knowledge structures, Journal of Management Studies, 29 (2), pp. 55-174.

Millier, P. (2000): Intuition can help in segmenting industrial markets, Industrial Marketing Management, 29, pp. 147-155.

Möller, K. and Svahn, S. (2003): Managing strategic nets, Marketing Theory, 3 (2), pp. 209-234.

Moriarty, R. T. and Reibstein, D. J. (1986): Benefit segmentation in industrial markets, Journal of Business Research, 14, pp. 463-486.

Mouzas, S. and Naudé, P. (2007): Network mobilizer, Journal of Business and Industrial Marketing, 22 (1), pp. 62-71.

Mouzas, S., Henneberg, S. C., and Naudé, P. (2008): Developing network insight, Industrial Marketing Management, 37 (2), pp. 166-179. 
Neill, S., McKee, D., and Rose, G.M. (2007): Developing the organization's sensemaking capability: Precursor to an adaptive strategic marketing response, Industrial Marketing Management, 36, pp. 731-744.

Neisser, U. (1967): Cognitive Psychology, Appleton-Century-Crafts, New York.

Normann, R. and Ramirez, R. (1993): From value chain to value constellation: Designing interactive strategy, Harvard Business Review, 71 (July/Aug), pp. 65-77.

Öberg, C., Henneberg, S., and Mouzas, S. (2007): Changing network pictures: The evidence from mergers \& acquisitions, Industrial Marketing Management, 36 (7), pp. 926-940.

Palmer, R.A. and Millier, P. (2004): Segmentation: Identification, intuition, and implementation, Industrial Marketing Management, 33, pp. 779-785.

Parolini, C. (1999): The Value Net, Wiley, Chichester.

Pick, H. Jr. (1999): Cognitive maps, in: Wilson, R.A. and Keil, F.C. (eds.): The MIT Encyclopedia of the Cognitive Sciences, The MIT Press, Cambridge Mass, pp. 135-137.

Piercy, N. F. and Morgan, N. A. (1993): Strategic and operational market segmentation: A managerial analysis, Journal of Strategic Marketing, 1, pp. 123-140.

Plank, R.E. (1985): A critical review of industrial market segmentation, Industrial Marketing Management, 14, pp. 79-91.

Powell, T.C. (1992): Organizational alignment as competitive advantage, Strategic Management Journal, 13, pp. 119-134.

Ragin, C. C. (1992): Casing and the process of social inquiry, in: What is a Case? Exploring the Foundations of Social Inquiry, Cambridge University Press, Cambridge, pp. 217-226.

Ritter T. (2000): A framework for analyzing interconnectedness of relationships, Industrial Marketing Management, 29 (4), pp. 317-327.

Shapiro, B. P. and Bonoma, T. V. (1984): How to segment industrial markets, Harvard Business Review, May-June, pp. 104-110.

Smircich, L. and Stubbart, C. (1985): Strategic management in an enacted world, Academy of Management Review, 10 (4), pp. 724-736.

Spender, J.C. (1989): Industry Recipes: The Nature and Sources of Managerial Judgement, Basil Blackwell, Oxford.

Stabell, C.B. and Fjeldstad, Ø. D. (1998): Configuring value for competitive advantage: On chains, shops, and networks, Strategic Management Journal, 19, pp. 413-437.

Starkey, K. and Madan, P. (2001): Bridging the relevance gap: Aligning stakeholders in the future of management research, British Journal of Management, 12 (Special Issue), pp. S3-S26.

Strauss, A. and Corbin, J. (1998): Basics of Qualitative Research, $2^{\text {nd }}$ Ed., Sage, Thousand Oaks.

Swart, J. and Henneberg, S.C. (2007): Dynamic knowledge nets - The 3C model, Journal of Knowledge Management, 11 (6), pp. 126-141.

Tolman, E.C. (1948): Cognitive maps in rats and man, Psychological Review, 55, pp. 189-208.

Tsoukas, H. (1996): The firm as a distributed knowledge system: A constructionist approach, Strategic Management Journal, 17, pp. 11-25.

Verhallen, T.M.M., Frambach, R.T., and Prabhu, J. (1998): Strategy-based segmentation of industrial markets", Industrial Marketing Management, 27, pp. 305-313.

Weick, K.E. (1995): Sensemaking in Organisations, Sage: Thousand Oaks.

Wind, Y. and Cardozo, R. (1974): Industrial market segmentation, Industrial Marketing Management, 3, pp. 153-166. 